\title{
The Study on A Hot Bath
}

\author{
Wenqian Jiang \\ North China Electric Power University, Baoding 071000, China \\ jwq163mail@163.com
}

Keywords: hot bathtub, heat preservation, law of thermodynamics

\begin{abstract}
Is there a way to keep the temperature even throughout the bathtub as close as possible to the initial temperature without wasting too much water? In this paper, the bathtub system can be abstracted as the water tank temperature control model. Because many factors cannot be taken into account at the same time, we take control variate method to simplify the problem.
\end{abstract}

\section{Introduction}

Every one of us may have had such experience: because the water gets cooler with the time passing, we have to stop the bathing enjoyment beforehand, when bathing in a bathtub, especially enjoying a long time bathing. If our family only have a simple water containment vessel, and we want to enjoy a long time comfortable bathing, is there a way to keep the temperature even throughout the bathtub as close as possible to the initial temperature without wasting too much water?

\section{Assumptions and Justifications}

To simplify the problem,we make some assumptions.

- System (the bathroom, the bathtub and the water supply ) doesn't have heat loss and the system is in a state of a equilibrium before the heat exchange process.

- Assume that the overflowed water in the time $t$ is not involved in the process of heat exchange[1].

- Suppose that the person is only moving in one exercise intensity, and when people is moving, the heat dissipating capacity per second is the same.

\section{Build the Model}

In the model, we don't consider the surface heat dissipation of water in bathtub, the motion of people in the bathtub and we think that the water in the bathtub is not full.

Under the above assumptions, the system observes the laws of transformation and conservation of energy. We can get

$$
\mathrm{Q}_{1}=\mathrm{Q}_{2}+\mathrm{Q}_{3}
$$

In the heat exchange process, when the temperature arises $\Delta \mathrm{T}$, the system will absorb heat $\Delta \mathrm{Q}$ from the outside environment. Then in the process, the heat capacity of the system is

$$
\Delta \mathrm{Q}=\mathrm{cm} \Delta \mathrm{T}
$$

The heat of the injected water is[2]

$$
\Delta Q_{1}=c m_{1} \Delta T_{1}=c m_{1}\left(T-T_{2}\right)
$$

The heat of the water in the bathtub is

$$
\Delta Q_{2}=c\left(\mathrm{~m}_{0}+\mathrm{qt}\right) \Delta T_{2}=c\left(\mathrm{~m}_{0}+\mathrm{qt}\right)\left(\mathrm{T}_{2}-T_{1}\right)
$$

Then,

$$
c m_{1}\left(\mathrm{~T}-\mathrm{T}_{2}\right)=c\left(\mathrm{~m}_{0}+\mathrm{qt}\right)\left(\mathrm{T}_{2}-T_{1}\right)+Q_{3}
$$

After simplified and approximate treatment, the equation can be got

$$
T_{2}=\left(\mathrm{T}_{0}-\mathrm{T}\right) \mathrm{m}_{0}^{\frac{q}{\Delta q}}\left(\mathrm{~m}_{0}+q t\right)^{\frac{q}{\Delta q}}+T
$$

When $\mathrm{T} 2=\mathrm{Ts}$, then 


$$
t=\frac{m_{0}}{\Delta q}\left[\left(\frac{T_{s}-T}{T_{0}-T}\right)^{-\frac{q}{\Delta q}}-1\right]
$$

And

$$
0<\frac{T_{s}-T}{T_{0}-T}<1
$$

Thus, the relationship between $t$ and the temperature of the water in bathtub can be obtained. In order to better address the model, we illustrate the above with an example. Suppose that $\mathrm{a}=1.7 \mathrm{~m}$, $\mathrm{b}=0.8 \mathrm{~m}, \mathrm{c}=0.7 \mathrm{~m}, \mathrm{~T}=80^{\circ} \mathrm{C}, \quad \mathrm{q}=0.1 \mathrm{~kg} / \mathrm{s}, \mathrm{T}_{\mathrm{c}}=30^{\circ} \mathrm{C}, \mathrm{Ts}=40^{\circ} \mathrm{C}$

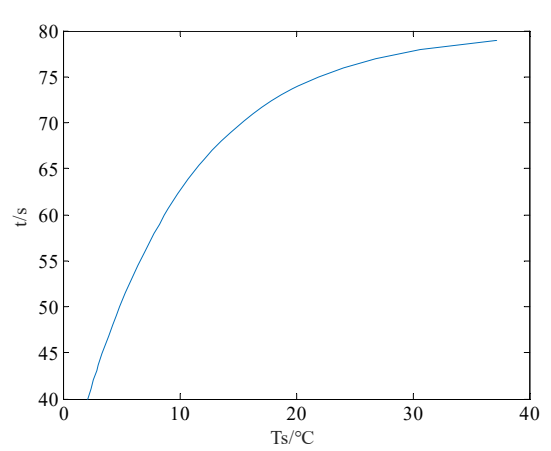

Figure 1: the relationship between $t$ and the temperature of the water in bathtub

As is shown in the Figure 1, when we add hot water to the bathtub, the temperature of the water in bath increases with time passing. [3]The higher the temperature is, the longer time and the more water is needed. The overflow of water is more at the same time. Thus, when the temperature of the water reaches the goal, we should reduce the flow of hot water to reduce water waste.

Using the eq (7), we can get

$$
\mathrm{t}=11.8 \mathrm{~min}
$$

When $\mathrm{t}$ is equal to $11.8 \mathrm{~min}$, the temperature of the water in bathtub has reached the goal, and the minimum flow rate is $97.94 \mathrm{~L}$. Then we just need to reduce the flow to maintain the target temperature. After referring to the relevant information, we can acquire the following equation under these specific condition[4]

We can get

$$
\mathrm{Q}_{3}=\mathrm{aba}\left(\mathrm{T}-\mathrm{T}_{\text {air }}\right)+2(\mathrm{ac}+\mathrm{bc}) \cdot \frac{\lambda\left(T_{m}-T_{\text {air }}\right)}{\delta}=\mathrm{cq}\left(\mathrm{T}-\mathrm{T}_{2}\right)
$$

$$
\mathrm{q}=0.27 \mathrm{~L} / \mathrm{min}
$$

We can see that $\mathrm{q}$ is small at this time, meaning that small flow of the hot water can maintain the initial temperature.

In the model, we mainly discuss when the other conditions are constant, how to adjust the hot water valve can minimum waste of water and keep the temperature of the water

in the bathtub as close as the target temperature. Then we want to explore what shape of the bathtub is in favour of heat preservation.

According to our observation of the existing shape of the bathtub on the market, there mainly are three kinds .

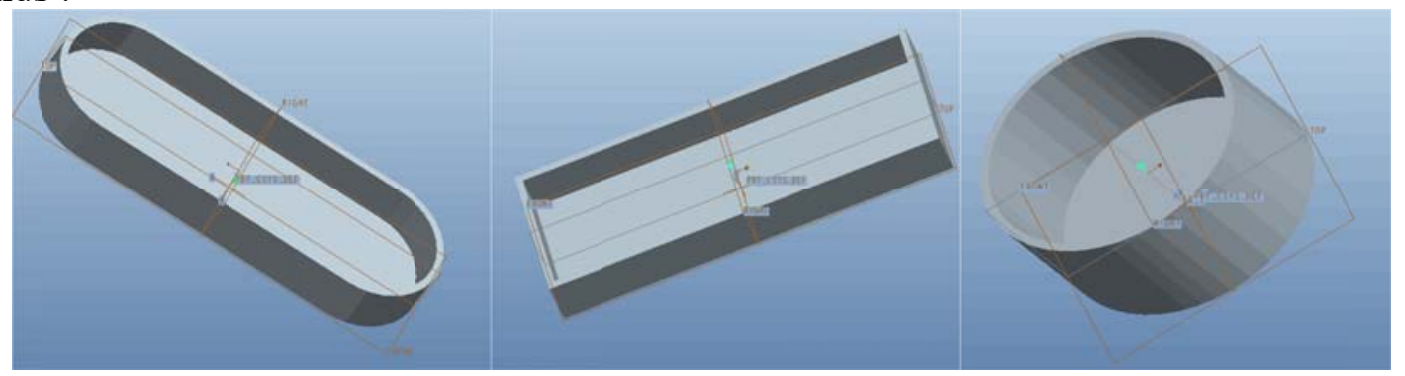

Figure 2: Three kinds of bathtubs

We calculate Q3 of different kinds of bathtubs in different volumes respectively. Then we can 
conclude that the oval bathtub is more perfect in heat preservation compare with the other two kinds.

\section{Conclusions}

Here we have a conclusion, as long as your family have a hot water tap you can enjoy a long time comfortable bath! First of all, you can choose the elliptic bathtub and you can add a little bubble bath when bathing, so that not only can you enjoy the bath ,but also insulation. Then according to the size of the bathtub, the temperature of the hot water and our specific strategy, choose different water flow to maintain the temperature of the water in the bath.

\section{References}

[1].Chen Zhihun,Wang Darui,Liu Qiujuan,Zhang Xuncai. Design or water temperature control Model in holothurian's aquaculture. Computer Engineering and Applications, 2007,43(32):225-22

[2].Yuri N.Toulouevski,Ilyaz Y.Zinurov.The Fundamental Laws and Calculating Formulae of Heat Transfer Processes.Innovation in Electric Arc Furnaces,2009:31-50.

[3].Liu Qingjie, Chen Guiming, Liu Xiaofang, ZHAN Jun. Research On Initialization Algorithms of Weights and Biases of BP Neural NetworkTeaching and Research Section 504,The Second Artillery Engineering College,Xi'an 710025,China.Journal of Southwest China Normal University(Natural Science Edition).2010(06):137-141.

[4].Lin Yahong,Formulas for calculating the evaporation of indoor swimming pools., Heating Ventilating \& Air Conditioning.2012(12) : 68-69. 